\title{
Green tea extract only affects markers of oxidative status postprandially: lasting antioxidant effect of flavonoid-free diet*
}

\author{
J. F. Young ${ }^{1}$, L. O. Dragsted ${ }^{2} \dagger$, J. Haraldsdóttir $^{1}$, B. Daneshvar ${ }^{2}$, M. A. Kall ${ }^{3}$, S. Loft ${ }^{4}$, L. Nilsson ${ }^{1}$, \\ S. E. Nielsen ${ }^{2}$, B. Mayer ${ }^{5}$, L. H. Skibsted ${ }^{6}$, T. Huynh-Ba ${ }^{7}$, A. Hermetter ${ }^{5}$ and B. Sandström ${ }^{1}$ \\ ${ }^{1}$ Research Department of Human Nutrition, Royal Veterinary and Agricultural University, Frederiksberg, Denmark \\ ${ }^{2}$ Institute of Food Safety and Toxicology, Danish Veterinary and Food Administration, S $\phi b o r g$, Denmark \\ ${ }^{3}$ Institute of Food Chemistry and Nutrition, Danish Veterinary and Food Administration, Søborg, Denmark \\ ${ }^{4}$ Institute of Public Health, University of Copenhagen, Copenhagen, Denmark \\ ${ }^{5}$ Institute of Biochemistry and Food Chemistry, Technical University of Graz, Graz, Austria \\ ${ }^{6}$ Food Chemistry, Department of Dairy and Food Science, Royal Veterinary and Agricultural University, Frederiksberg, \\ Denmark \\ ${ }^{7}$ Nestlé Research Centre, Nestec Ltd., 1000 Lausanne 26, Switzerland
}

(Received 30 November 2000 - Revised 7 September 2001 - Accepted 8 December 2001)

\begin{abstract}
Epidemiological studies suggest that foods rich in flavonoids might reduce the risk of cardiovascular disease and cancer. The objective of the present study was to investigate the effect of green tea extract (GTE) used as a food antioxidant on markers of oxidative status after dietary depletion of flavonoids and catechins. The study was designed as a $2 \times 3$ weeks blinded human cross-over intervention study (eight smokers, eight non-smokers) with GTE corresponding to a daily intake of $18.6 \mathrm{mg}$ catechins/d. The GTE was incorporated into meat patties and consumed with a strictly controlled diet otherwise low in flavonoids. GTE intervention increased plasma antioxidant capacity from 1.35 to $1.56(P<0.02)$ in postprandially collected plasma, most prominently in smokers. The intervention did not significantly affect markers in fasting blood samples, including plasma or haemoglobin protein oxidation, plasma oxidation lagtime, or activities of the erythrocyte superoxide dismutase, glutathione peroxidase, glutathione reductase and catalase. Neither were fasting plasma triacylglycerol, cholesterol, $\alpha$-tocopherol, retinol, $\beta$-carotene, or ascorbic acid affected by intervention. Urinary 8-oxo-deoxyguanosine excretion was also unaffected. Catechins from the extract were excreted into urine with a half-life of less than $2 \mathrm{~h}$ in accordance with the short-term effects on plasma antioxidant capacity. Since no long-term effects of GTE were observed, the study essentially served as a fruit and vegetables depletion study. The overall effect of the 10-week period without dietary fruits and vegetables was a decrease in oxidative damage to DNA, blood proteins, and plasma lipids, concomitantly with marked changes in antioxidative defence.
\end{abstract}

Green tea extract intervention: Dietary depletion of fruits and vegetables: Biomarkers of oxidative damage: Biomarkers of antioxidative defence: Protein oxidation

Consumption of fruit and vegetables is widely encouraged because of the epidemiological indications of a relationship between increased intake and reduced risk of cancer and cardiovascular diseases. A major group of antioxidative compounds in fruit and vegetables, the polyphenols, has been suggested to contribute to these beneficial effects
(Hertog et al. 1993a, 1994, 1995). In a Dutch population, tea was found to be the main dietary source of five selected flavonoids (Hertog et al. 1993b). However, the beneficial effects of tea on cancer and cardiovascular diseases remain controversial (Goldbohm et al. 1996; Katan, 1997; Kohlmeier et al. 1997).

\footnotetext{
Abbreviations: AAS, 2-amino-adipic semialdehyde; EC, epicatechin; EGC, epigallocatechin; GTE, green tea extract; 8-oxo-dG, 8-oxo-deoxyguanosine.

* The study has been carried out with financial support in part from a Danish Food Technology grant (FØTEK2, 'Antioxidants from plants') and in part from the Commission of the European Communities, Agriculture and Fisheries (FAIR) specific RTD programme, CT 95-0158 'Natural Antioxidants from Foods'. It does not necessarily reflect its views and in no way anticipates the Commission's future policy in this area.

$\dagger$ Corresponding author: L. O. Dragsted, present address Mørkhøj Bygade 19, DK-2860, Søborg, Denmark, fax +45 33956001 , email lod@fdir.dk
} 
As much as $26-30 \%$ of the DM of fresh tea leaves may consist of flavonoids (Lin et al. 1998), among which the catechins are the most abundant. During the manufacture of black tea (a fermentation process) catechins are progressively oxidised by polyphenol oxidase, to form polymerisation products (Lin et al. 1998). The catechins in tea have a potent antioxidative capacity in model systems, including radical scavenging (Yen \& Chen, 1995; Gardner et al. 1998) and provide protection against oxidative changes in plasma (Ishikawa et al. 1997; Lotito \& Fraga, 1998) and LDL (Ishikawa et al. 1997; Zhang et al. 1997). Some studies indicate that green tea is a more potent antioxidant than black tea in in vitro model systems (Yen \& Chen, 1995; Gardner et al. 1998), probably due to its higher content of catechins and lack of polymerisation products (Lin et al. 1998).

If catechins can be incorporated into plasma they may be expected to affect the antioxidative status. Animal studies on pure catechins in rats have shown that these compounds are absorbed and transported to the tissues (Nakagawa \& Miyazawa, 1997) and experiments with human subjects have shown that catechins are found in plasma (Nakagawa et al. 1997) and excreted into the urine (Das, 1971). Consumption of both green and black tea was found to increase plasma antioxidant capacity within 30-50 min (Serafini et al. 1996), but over a longer time scale (4 weeks) no effects on antioxidative parameters in blood were observed apart from a slight increase in antioxidative activity in plasma after green tea consumption (van het Hof et al. 1997).

If tea consumption has an effect on the antioxidative system an extract of tea could be expected to exhibit a similar effect. The present study investigated the effect of a green tea extract (GTE) on markers of oxidative status in blood and urine in a blinded double cross-over study with complete control of all dietary intakes. The GTE was incorporated into meat patties at a concentration of $1000 \mathrm{mg} / \mathrm{kg}$, which has been demonstrated to protect against oxidative changes in dried chicken meat (Nissen et al. 2000).

In order to study individuals with different levels of oxidative stress the study included both smokers and non-smokers.

\section{Methods}

Subjects

Sixteen men volunteered for the study including eight nonsmokers and eight smokers (10-15 cigarettes/d). Average age was 23 (range 20-31) years and average BMI was 22.7 (range $19.5-25 \cdot 7$ ) $\mathrm{kg} / \mathrm{m}^{2}$. None of the subjects had any chronic illness. Subjects received oral and written information about the study, and gave their written consent. The study was approved by the local Research Ethics Committee of Copenhagen and Frederiksberg (Journal number KF01-342/97).

\section{Study design and diet}

The study design is illustrated in Fig. 1. It was a doubleblind randomised $2 \times 3$ week cross-over with 2 weeks wash-out before each intervention. Subjects were divided into groups A and B, with four smokers and four non-smokers in each group. A standardised diet with a low flavonoid content, including $200 \mathrm{~g}$ meat patties/10 MJ, was served for the $2 \times 3$ week study periods. For one of the 3-week periods the subjects consumed GTE incorporated into meat patties at a concentration of $1000 \mathrm{mg} / \mathrm{kg}$. During the wash-out weeks the subjects excluded flavonoid-containing foods from their diet. Tea, wine, spices, chocolate, cocoa and all products containing fruits, berries and vegetables, except potatoes and carrots were excluded from their diet. A list of allowed dietary items was distributed to the participants, which included all meats, fish, shellfish, grain products (including whole grain) such as

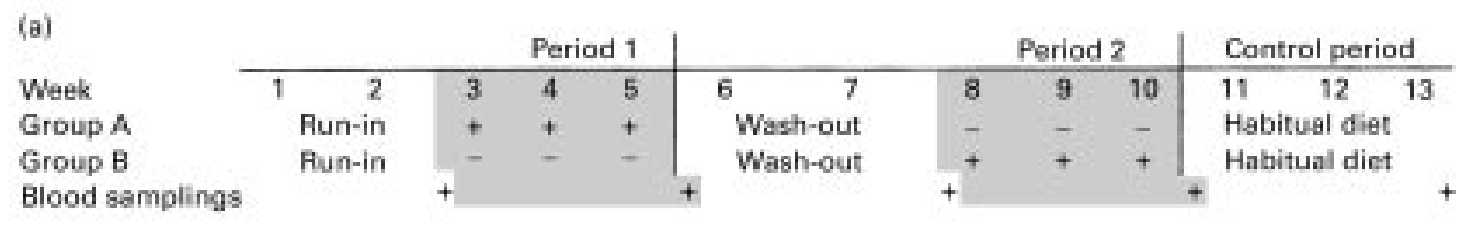

(b) Day of intervention in each 3 week period

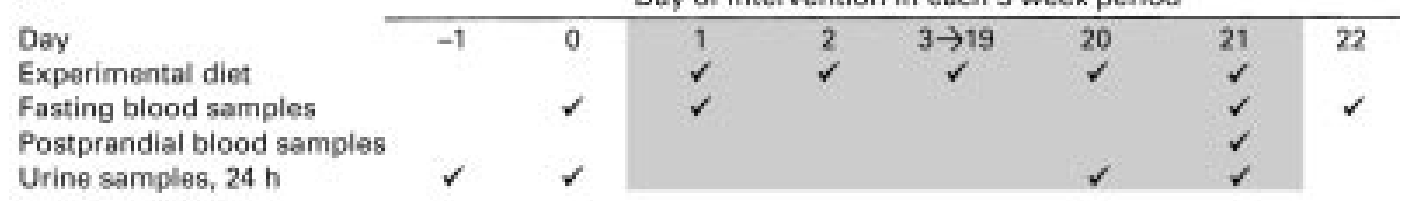

Fig. 1. Study design. (a) Depiction of the overall design over the entire 13-week period, including two sequential periods, each with an initial 2-weeks wash-out followed by a 3-weeks cross-over intervention, and a final control period. (b) Depiction of the exact sampling times for blood and urine during each of periods 1 and 2 . (+) Intervention with green tea extract; $(-)$ sample collection. 
Table 1. Composition of the experimental diet $(\mathrm{g} / \mathrm{d})$ at an energy intake of $10 \mathrm{MJ} / \mathrm{d}$

\begin{tabular}{|c|c|c|c|c|c|c|c|c|}
\hline & Component & Menu 1 & Menu 2 & Menu 3 & Menu 4 & Menu 5 & Menu 6 & Menu 7 \\
\hline \multirow[t]{4}{*}{ Breakfast } & Bread roll with carrots & 77 & 77 & 77 & 77 & 77 & 77 & 77 \\
\hline & Cheese & 25 & 25 & 25 & 25 & 25 & 25 & 25 \\
\hline & Sour milk & 170 & 170 & 170 & 170 & 170 & 170 & 170 \\
\hline & Rye breadcrumbs & 30 & 30 & 30 & 30 & 30 & 50 & 50 \\
\hline \multirow[t]{8}{*}{ Lunch } & Rye bread & 100 & 100 & 100 & 100 & 100 & 100 & 100 \\
\hline & Butter & 6 & 6 & 6 & 6 & 6 & 6 & 6 \\
\hline & Meat patties & 50 & 50 & 50 & 50 & 50 & 50 & 50 \\
\hline & Tuna salad & 34 & & 34 & & & & \\
\hline & Potatoes & & 50 & & & 50 & & \\
\hline & Ham salad & & & & 44 & & & \\
\hline & Roast beef & & & & & & 30 & 30 \\
\hline & Carrot salad & 100 & 100 & 100 & 100 & 100 & 100 & 100 \\
\hline \multirow[t]{9}{*}{ Dinner } & Meat patties & 150 & 150 & 150 & 150 & 150 & 150 & 150 \\
\hline & Mashed potatoes & 250 & & & & & 250 & \\
\hline & Pasta & & 70 & & & & & \\
\hline & Potatoes & & & 200 & & 200 & & \\
\hline & Rice & & & & 70 & & & 70 \\
\hline & Stock & 150 & & & & & 150 & \\
\hline & Brown sauce & & & 153 & & 153 & & \\
\hline & Cheese sauce & & 160 & & & & & \\
\hline & Chicken sauce & & & & 180 & & & 180 \\
\hline \multirow[t]{4}{*}{ Snack } & Bread roll with carrots & 77 & 77 & 77 & 77 & 77 & 77 & 77 \\
\hline & Butter & 6 & 6 & 6 & 6 & 6 & & \\
\hline & Sponge cake & 100 & & 100 & & 100 & & \\
\hline & Carrot cake & & 100 & & 100 & & 100 & 100 \\
\hline Milk & & 250 & 250 & 250 & 250 & 250 & 250 & 250 \\
\hline
\end{tabular}

breads and pasta, eggs, potatoes, carrots, freeze dried coffee, mineral water and tap water. The freeze dried coffee was analysed by HPLC and found to be free from catechins. The diet during intervention consisted of seven menus consumed each week from Monday to Sunday (Table 1). The macronutrient and selected micronutrient contents were calculated using a computer program (Dankost) which is based on the Danish Veterinary and Food Administration composition database (Møller, 1989) (Table 2). Each subject's energy requirement was estimated from body weight and degree of physical activity. All meals were prepared at the department in individual portions according to energy requirement. One of the daily main meals was taken at the department while the remaining (cold) meals were provided daily for intake at home. Subjects were instructed to return any leftovers to the department for weighing and subtraction from planned

Table 2. The macronutrient and selected micronutrient content of the experimental diet (per 10 MJ)*

\begin{tabular}{|c|c|c|}
\hline \multirow[b]{2}{*}{ Nutrient } & \multicolumn{2}{|c|}{ Content } \\
\hline & per $10 \mathrm{MJ}$ & \% Energy \\
\hline Protein (g) & 91 & 16 \\
\hline Fat $(\mathrm{g})$ & 99 & 37 \\
\hline Carbohydrate (g) & 277 & 47 \\
\hline Vitamin E (tocopherol equivalents) & 2.9 & \\
\hline Vitamin C (mg)† & $12 \cdot 6$ & \\
\hline Vitamin A (retinol equivalents) & 3180 & \\
\hline$\beta$-Carotene $(\mathrm{mg}) \dagger$ & $11 \cdot 2$ & \\
\hline$\alpha$-Carotene $(\mathrm{mg}) \dagger$ & $3 \cdot 6$ & \\
\hline Lutein $(\mathrm{mg}) \dagger$ & 0.49 & \\
\hline
\end{tabular}

* For details of diet and procedures, see Table 1 and p. 344.

$\uparrow$ Analysed by HPLC; the remaining nutrients were calculated. intake and were asked daily about compliance. Freezedried coffee powder was provided for preparation of coffee. Coffee intake was recorded and varied between subjects but was held constant over the 6 weeks. No food or drink other than that provided from the department was allowed. Fasting blood samples were collected during each period on the morning of day $0,1,21$ and 22 , thus reflecting the preceding $24 \mathrm{~h}$, i.e. day 0 and 1 samples reflect baseline concentrations before intervention (days -1 and 0 , respectively) and days 21 and 22 samples reflect the last $2 \mathrm{~d}$ of each intervention period (days 20 and 21, respectively) (see Fig. 1(b)). In addition, one blood sample was taken $2.5 \mathrm{~h}$ after the hot meal at midday on day 21 of each period. The samples will be referred to in the text according to the $24 \mathrm{~h}$ they are reflecting within each period. A final blood sample was collected after week 13 when the subjects had been on their habitual diet for 3 weeks after the last intervention. This sample was collected to represent the participant's natural background. Twenty-four hour urine samples were collected at baseline, i.e. the $2 \mathrm{~d}$ before the intervention (days -1 and 0 ) and during the last $2 \mathrm{~d}$ of intervention (days 20 and 21). Body weight was determined before and after each intervention period.

\section{Green tea extract and pork meat patties}

Extract of Chinese green tea (Licosa-P/Thé chinois) was produced using the process described in a patent (Aeschbach \& Rossi, 1994). The extract was a hydrophilic mechanical extract obtained by pressing the tea on a hydraulic laboratory press using propylene glycol as the carrier. The total polyphenol content of the tea extract was 
Table 3. Daily intake of some polyphenols from green tea extract $(1000 \mathrm{mg} / \mathrm{kg} \text { in the } 200 \mathrm{~g} \text { meat patties served per } 10 \mathrm{MJ})^{*}$

\begin{tabular}{lc}
\hline Compound & Daily intake $(\mathrm{mg} / 10 \mathrm{MJ})$ \\
\hline Catechin & Not detected \\
Epicatechin & 1.68 \\
Epicatechin gallate & $2 \cdot 78$ \\
Epigallocatechin & $5 \cdot 14$ \\
Epigallocatechin gallate & 9.04 \\
Total phenolicst & 23.5 \\
\hline
\end{tabular}

* For details of diet and procedures, see Table 1 and pp. 344-345.

†Total phenolic content was determined by the Folin-Ciocalteu method as $\mathrm{mg}$ gallic acid equivalent/g extract. Catechins were determined by HPLC.

$117.3 \mathrm{mg}$ gallic acid equivalent/g extract. Catechins content as determined by HPLC are shown in Table 3 .

GTE was incorporated at $1000 \mathrm{mg} / \mathrm{kg}$ in pork meat patties, which were produced on a pilot scale using pork meat ( $25 \%$ fat), water and salt as ingredients. Reference meat patties containing no added GTE were also produced. The process consisted in tempering of the meat (at $\left.-2^{\circ} \mathrm{C}\right)$, mixing all the ingredients, grinding $(3 \mathrm{~mm})$, patty forming (approximately $40 \mathrm{~g}$ each patty) and frying (belt fryer, no use of additional fat or oil). Meat patties were frozen at $-25^{\circ} \mathrm{C}$, packed under vacuum in plastic pouches and stored at $-25^{\circ} \mathrm{C}$ until use. A microbiological control was performed on the finished products.

\section{Collection of urine and determination of 8-oxo- deoxyguanosine}

Twenty-four hour urine samples were collected in 2.51 plastic bottles. Fifty $\mathrm{ml}$ of $1 \mathrm{~mol} / \mathrm{l} \mathrm{HCl}$ and $10 \mathrm{ml}$ of $10 \%$ ascorbic acid were added to each 2.51 bottle to increase stability during collection. Urines were weighed, density determined, $\mathrm{pH}$ adjusted to $3-4$ with $1 \mathrm{~mol} / \mathrm{l} \mathrm{HCl}$ and stored at $-80^{\circ} \mathrm{C}$ until analysis. Urinary concentrations of 8-oxo-deoxyguanosine (8-oxo-dG), a marker of total oxidatively damaged DNA in the body, were determined by column-switching HPLC with electrochemical detection as described previously (Loft \& Poulsen, 1999).

\section{Collection of blood samples and separation of erythrocytes and plasma}

Venous blood samples were taken in the morning after at least $12 \mathrm{~h}$ of fasting. An additional postprandial sample was drawn on day 21 of each intervention, $2.5 \mathrm{~h}$ after consumption of the cooked meal. Blood samples were taken in EDTA-coated tubes after supine resting for $10 \mathrm{~min}$. All subjects abstained from alcohol for at least $24 \mathrm{~h}$ before blood sampling, and the smokers abstained from smoking for at least $8 \mathrm{~h}$ before fasting blood samples, and $4.5 \mathrm{~h}$ before sampling of non-fasting blood samples. Subjects were instructed to avoid heavy physical activity for $36 \mathrm{~h}$ before blood sampling. Plasma samples for 2-amino-adipic semialdehyde (AAS) determination were centrifuged at $1500 \mathrm{~g}$ for $10 \mathrm{~min}$ at room temperature. Erythrocytes were washed three times with 3 vol. $0.9 \% \mathrm{NaCl}$, resuspended in 1 vol. ultrapure (resistance $>18 \mathrm{Mohm}$ ) water for lysis, and then stored at $-80^{\circ} \mathrm{C}$ until analysis. Samples for $\alpha$-tocopherol, retinol, $\beta$-carotene, antioxidant capacity and vitamin $\mathrm{C}$ determination were protected from light exposure and kept on ice. Samples were centrifuged at $3000 \mathrm{~g}$ for $15 \mathrm{~min}$ at $4^{\circ} \mathrm{C}$, and plasma for vitamin $\mathrm{C}$ analyses were added to 1 volume of $10 \%$ meta-phosphoric acid before freezing. Plasma was saturated with $\mathrm{N}_{2}$ gas and stored at $-80^{\circ} \mathrm{C}$ until analysis for antioxidant capacity (maximum $7 \mathrm{~d}$ ), retinol, $\alpha$-tocopherol and $\beta$-carotene (maximum 7 months), cholesterol and triacylglycerol (20 months).

\section{Ascorbate, plasma protein oxidation and antioxidant enzymes}

Plasma and dietary samples were analysed for ascorbate (Kall \& Andersen, 1999) and plasma proteins were analysed for oxidised lysine residues (Daneshvar et al. 1997) by HPLC as described previously. Erythrocyte lysates were also analysed for protein oxidation products and for the activities of catalase, superoxide dismutase, glutathione peroxidase and glutathione reductase by methods detailed previously (Nielsen et al. 1999). Inter-series CV was less than $10 \%$ for all of these analyses.

\section{Plasma oxidation lagtime and plasma antioxidant capacity}

Oxidation of lipoproteins in unfractionated plasma was continuously measured by a fluorescence method as described previously (Hofer et al. 1995).

The postprandial samples collected on day 21 of each period were used immediately for determination of plasma antioxidant activity. Fifty $\mu$ l of plasma (or controls: $10 \mu 12 \mathrm{mmol} / \mathrm{l}$ Trolox $+40 \mu \mathrm{l}$ buffer or $50 \mu \mathrm{l}$ buffer) were added to $2.45 \mathrm{ml} 1.33 \mathrm{mmol} / \mathrm{l}$ methyl linoleate emulsion in $5.0 \mathrm{mmol} / \mathrm{l}$ oxygen-saturated $\mathrm{PBS}(\mathrm{pH} 7.4$ ) containing $0.1 \%$ Tween 20 and the oxygen consumption was determined as described previously (Jørgensen \& Skibsted, 1993). Antioxidative capacity was estimated by calculating the area under oxygen consumption curves and the influence of plasma was expressed as an antioxidative index (I) relative to samples including Trolox:

$$
\begin{aligned}
& \text { I }_{\text {oxygen consumption relative to reference including Trolox }} \\
& \text { = area (plasma)/area (reference including Trolox). }
\end{aligned}
$$

\section{Determination of plasma retinol, $\alpha$-tocopherol, $\beta$-carotene, triacylglycerol and cholesterol}

Plasma retinol, $\alpha$-tocopherol and $\beta$-carotene were determined by a contract laboratory (Medi-Lab, Copenhagen, Denmark) using a standard HPLC-procedure (Thurnham et al. 1988). Intra-series CV was $4 \%, 4 \%$ and $7 \%$ and inter-series variation was $5 \%, 5 \%$ and $10 \%$, respectively, for retinol, $\alpha$-tocopherol and $\beta$-carotene. Plasma triacylglycerol (kit no. 0736791 Unimate5, Roche) and cholesterol (kit no. CHOD-PAP 2016630; Boehringer Mannheim, Mannheim, Germany) were determined on a Cobas Mira + (Roche, Basel, Switzerland). Carotenoids in the 
experimental diet were determined as described by Hart \& Scott (1995).

\section{Follow-up studies}

Two small follow-up studies were performed in order to assess catechin uptake and whether catechins from meat patties containing GTE were absorbed to the same extent as catechins from GTE given in a water-alcohol mixture.

In the first study five volunteers consumed an experimental diet with a low content of flavonoids as described in the main study for $4 \mathrm{~d}$. On the second day in the morning they voided a spot urine sample and subsequently ingested $2 \mathrm{~g}$ GTE in $25 \mathrm{ml}$ water-ethanol (2:1). Total urines were collected 4, 24 and $48 \mathrm{~h}$ after GTE intake.

The second study was a $3 \times 1 \mathrm{~d}$ cross-over, where three volunteers consumed a low-catechin diet as described in the main study for $2 \mathrm{~d}$ (day 1-2). On days 3-5, they were each day given either $500 \mathrm{mg}$ GTE in $10 \mathrm{ml}$ waterethanol (2:1), $500 \mathrm{mg}$ GTE in meat patties stored at $-25^{\circ} \mathrm{C}$ for 12 months (from the main study), or $500 \mathrm{mg}$ GTE mixed into freshly prepared meat patties. Urine samples $(24 \mathrm{~h})$ were collected from each volunteer during days $2-5$. The volunteers in these studies were different from those in the main study.

The containers for urine collection in both follow-up studies were prepared as described for the main study and were additionally filled with Ar. Immediately at the end of each collection period the urine samples were saturated with $\mathrm{Ar}$ and analysed for catechins.

\section{HPLC analyses of urine samples, green tea extract and instant coffee for content of epicatechin and epigallocatechin}

The content of epicatechin (EC) and epigallocatechin (EGC) was determined in the GTE, in the freeze dried coffee, and in fresh urine samples from the follow-up studies. The assay used for analysis was similar to those previously described for other flavonoids (Nielsen \& Dragsted, 1998a,b) with respect to enzymic hydrolysis and solid phase extraction.

Enzymically hydrolysed urine samples, GTE or coffee were suspended in $5 \%$ acetonitrile in water before addition of internal standard $(10 \mathrm{mg}$ catechin/l) and subjected to solid phase extraction. The HPLC-MS system consisted of a Hewlett Packard (Waldbronn, Germany) 1090 system with a a MSD 1100 mass spectrometric detector. The columns used were a Zorbax SB-C8 $(4.6 \times 75 \mathrm{~mm}$, $3.5 \mu \mathrm{m})$ column as column 1 and a Purospher RP-18 $(4 \times 125 \mathrm{~mm}, 5 \mu \mathrm{m})$ column with guard cartridge $(4 \times 4 \mathrm{~mm}, 5 \mu \mathrm{m})$ as column 2 (Hewlett Packard). Column temperature was maintained constant at $37^{\circ} \mathrm{C}$ using a thermostatically controlled column compartment. U.v. detection was carried out at $280 \mathrm{~nm}$, with peak scanning between 190 and $600 \mathrm{~nm}$ ( $2 \mathrm{~nm}$ step). The MSdetection was performed by single-ion monitoring using atmospheric pressure ionisation with electrospray interface in positive mode. The drying gas $\left(\mathrm{N}_{2}\right)$ was heated to $350{ }^{\circ} \mathrm{C}$ and introduced at a flow-rate of $10.01 / \mathrm{min}$. Nebuliser pressure was set to $30 \mathrm{psig}$ and capillary voltage to $4000 \mathrm{~V}$. The mobile phases used for HPLC were (flow of $0.4 \mathrm{ml} / \mathrm{min}$ ): A, $1 \%$ aqueous formic acid; B, $100 \%$ acetonitrile; C, $100 \%$ methanol. With the automatic six-port columnswitching valve in position 1, the sample was injected onto column 1 and eluted through the diodearray detector, bypassing column 2 and the MS-detector, with a following linear gradient of mobile phase B in A (v/v): $5 \%$ to $15 \%$ from 0 to $5 \mathrm{~min} ; 15 \%$ to $25 \%$ from 5 to $14 \mathrm{~min}$. Between $14 \cdot 1-15 \min 100 \% \mathrm{~B}$ was applied resulting in a short wash of column 1. EGC was eluted from column 1 at $7.5 \mathrm{~min}$. By switching the column switching valve from position 1 to 2 at $7.2 \mathrm{~min}$ and back to position 1 at $7.8 \mathrm{~min}$, this compound was eluted onto the second column. This procedure was repeated between $8.3-8.8 \mathrm{~min}$ and $9.5-10.0 \mathrm{~min}$ for catechin (internal standard) and EC, respectively. From 15.1-23 min column 1 was preconditioned with pure mobile phase A, and after shifting to column 2 at $21.5 \mathrm{~min}$, elution of the tea catechins through the MSdetector was initiated using the following gradient of mobile phase $\mathrm{C}$ in $\mathrm{A}(\mathrm{v} / \mathrm{v}): 24 \mathrm{~min}, 25 \% \mathrm{C} ; 28-37 \mathrm{~min}$, $32 \% \mathrm{C} ; 37.5-39 \mathrm{~min}, 100 \% \mathrm{C} ; 39.1 \mathrm{~min}, 25 \%$ C. A freshly prepared standard solution containing EC, EGC and catechin was analysed before and after each run to ensure a correct column-switching schedule. The EC and EGC detected were corrected for the internal standard (catechin) recovery in each urine sample.

\section{Statistics}

The statistical analysis of biomarkers in the cross-over study was done by paired $t$ tests according to Pocock (1998). Significant period effects were observed for plasma ascorbate, 8-oxo-dG in urine and plasma antioxidant capacity, and corrections were made according to Pocock (1998). Plasma oxidation lagtime, $\beta$-carotene and AAS in erythrocyte lysates were analysed by comparing groups A and B after the first period using a two-sample $t$ test due to period-effect interactions. The effect of smoking was analysed by two-sample $t$ tests, comparing smokers and non-smokers using the baseline samples collected after run-in. The effect of intervention on smokers and non-smokers was analysed separately using the same procedure as outlined above for the whole study. Multivariate ANOVA with a repeated statement for the day on intervention was performed for all biomarkers to additionally test for time trends during the whole intervention trial using the SAS statistical package (SAS 6.12; SAS Institute Inc., Cary, NC). A $P$-value of $<0.05$ was considered statistically significant.

\section{Results}

\section{Subjects, baseline comparisons and influence of smoking status}

All subjects were weight-stable, i.e. body weight changed less than $1 \mathrm{~kg}$ during the total experimental period for each subject. Group A and B differed with respect to plasma oxidation lagtime at week 2 . There were no other differences between the groups after run-in. Smoking did not influence any of the markers after the 2 week run-in 
Table 4. Comparison of oxidative status markers in blood or urine at the end of 3 weeks intake of the experimental diet without and with green tea extract $(1000 \mathrm{mg} / \mathrm{kg})$ in meat patties $(200 \mathrm{~g} / 10 \mathrm{MJ}$ per d) in sixteen subjects (average of blood samples from 2 successive days)*

(Mean values with their standard deviations)

\begin{tabular}{|c|c|c|c|c|c|c|}
\hline \multirow[b]{2}{*}{ Biomarker } & \multicolumn{2}{|c|}{ Basal diet } & \multicolumn{2}{|c|}{ Tea extract } & \multicolumn{2}{|c|}{ Paired difference } \\
\hline & Mean & SD & Mean & SD & Mean & $95 \% \mathrm{Cl}$ \\
\hline Change in oxidation lagtime $(\mathrm{min}) \dagger$ & $32 \cdot 6 \dagger \ddagger$ & $26 \cdot 0$ & $42 \cdot 0 \dagger \ddagger$ & $30 \cdot 0$ & $\dagger \ddagger$ & \\
\hline 8-Oxo-deoxyguanosine (pmol/24 h per kg body wt) & 257 & 79 & 261 & 81 & $4.3 \S$ & $-31.4,39.9$ \\
\hline Plasma antioxidant capacity $\left(\mathrm{I}_{\text {ref }}^{\|}\right)$ & $1 \cdot 35$ & 0.25 & 1.56 & 0.34 & $0 \cdot 21 \S \rrbracket$ & $0.021,0.41$ \\
\hline AASpl (nmol/mg protein) & $18 \cdot 8$ & $3 \cdot 8$ & $19 \cdot 5$ & $3 \cdot 7$ & 0.75 & $-1 \cdot 78,3 \cdot 28$ \\
\hline AAShb (nmol/mg protein) & $36 \cdot 2 \ddagger$ & 4.9 & $36 \cdot 4 \ddagger$ & 4.5 & $\ddagger$ & \\
\hline GGShb (nmol/mg protein) & 21.9 & 4.0 & 21.5 & $3 \cdot 7$ & -0.39 & $-2 \cdot 25,1.46$ \\
\hline $\mathrm{Gpx}(\mathrm{U} / \mathrm{g} \mathrm{Hb})$ & $37 \cdot 9$ & $9 \cdot 8$ & $37 \cdot 4$ & $10 \cdot 8$ & -0.48 & $-5 \cdot 58,4 \cdot 61$ \\
\hline Glutathione reductase $(\mathrm{U} / \mathrm{g} \mathrm{Hb})$ & $7 \cdot 05$ & $1 \cdot 2$ & 7.06 & $1 \cdot 2$ & 0.01 & $-0 \cdot 13,0 \cdot 16$ \\
\hline Superoxide dismutase $(\mathrm{U} / \mathrm{g} \mathrm{Hb})$ & 1009 & 149 & 1035 & 139 & $25 \cdot 9$ & $-3 \cdot 7,55 \cdot 5$ \\
\hline Catalase (U/g Hb) & $12 \cdot 0$ & $2 \cdot 1$ & $11 \cdot 4$ & $1 \cdot 2$ & -0.65 & $-1.54,0.24$ \\
\hline
\end{tabular}

AASpl, Plasma 2-amino-adipic semialdehyde; AAShb, 2-amino-adipic semialdehyde in erythrocyte lysates; GGShb, $\gamma$-glutamyl semialdehyde in erythrocyte lysates; Gpx, glutathione peroxidase, $\mathrm{Hb}$, haemoglobin.

* For details of diet and procedures, see Table 1 and pp. 344-345.

† Due to a significant difference between the groups at baseline, the change in plasma oxidation lagtime from start to end of period I is shown.

†There was significant period-effect interaction for this marker, so statistical analysis was performed between groups in period I only.

$\S$ There was a significant period effect for this marker, and statistical analysis was performed according to Pocock (1998).

$\| I_{\text {ref, }}$ antioxidative capacity relative to reference including Trolox (see p. 346).

I There was a significant effect of green tea extract intervention $(P<0.02)$.

period, but in the sample representing habitual diet (13 weeks), plasma ascorbate was significantly lower in smokers.

\section{Biomarkers of oxidative damage and antioxidant defence}

Effects on blood and urine parameters after 3 weeks of experimental diet with or without addition of tea extract to a low-flavonoid diet are shown in Tables 4 and 5 . There was no significant effect of intervention with tea extract on plasma protein oxidation (plasma AAS) or plasma oxidation lagtime analysed as delta change for each individual from beginning to end of period 1 .

In erythrocytes no effect of GTE intervention was observed on markers of protein oxidation (AAS and $\gamma$-glu- tamyl semialdehyde in erythrocytelysates), and the excretion of 8-oxo-dG in urine was not affected either.

There was a significant decrease in plasma AAS and in $\gamma$-glutamyl semialdehyde in erythrocyte lysates when the samples representing the participants' habitual diet (week 13) were compared with the samples collected at the end of the periods with restricted diet. The downward trends in plasma AAS (Fig. 2(a)) and in AAS in erythrocyte lysates during the period with restricted diets were also significant as determined by repeated measures ANOVA. Plasma oxidation lagtimes increased significantly in each strictly controlled period, and also overall during the 10 weeks with a restricted diet as compared with habitual diet (Table 6 and Fig. 2(c)). The urinary excretion of 8 -oxo-dG decreased significantly during each of the two

Table 5. Comparison of plasma lipid status markers and plasma antioxidant vitamins at the end of 3 weeks intake of experimental diet without or with green tea extract $(1000 \mathrm{mg} / \mathrm{kg})$ in meat patties $(200 \mathrm{~g} / 10 \mathrm{MJ}$ per $\mathrm{d}$ ) in sixteen subjects (each represented by the average of blood samples from 2 successive days)*

(Mean values with their standard deviations)

\begin{tabular}{|c|c|c|c|c|c|c|}
\hline \multirow[b]{2}{*}{ Biomarker } & \multicolumn{2}{|c|}{ Basal diet } & \multicolumn{2}{|c|}{ Tea extract } & \multicolumn{2}{|c|}{ Paired difference } \\
\hline & Mean & SD & Mean & SD & Mean & $95 \% \mathrm{Cl}$ \\
\hline Triacylglycerol (mmol/l) & 1.02 & 0.23 & 1.04 & 0.22 & 0.019 & $-0.036,0.074$ \\
\hline Cholesterol (mmol/l) & $4 \cdot 25$ & $1 \cdot 20$ & $4 \cdot 21$ & 1.03 & -0.047 & $-0.20,0.11$ \\
\hline Retinol ( $\mu \mathrm{mol} / \mathrm{l})$ & 1.73 & 0.31 & 1.75 & 0.25 & 0.019 & $-0.082,0.121$ \\
\hline Vitamin C (mg/l) & $2 \cdot 36$ & 0.88 & $2 \cdot 50$ & 1.06 & $0.14 \dagger$ & $-0.52,0.80$ \\
\hline$\beta$-Carotene $(\mu \mathrm{mol} / \mathrm{l})$ & $1.43 \ddagger$ & 0.58 & $2 \cdot 07 \ddagger$ & 0.60 & $\ddagger \S$ & \\
\hline$\alpha$-Tocopherol $(\mu \mathrm{mol} / \mathrm{l})$ & $17 \cdot 6$ & $4 \cdot 2$ & $17 \cdot 4$ & $4 \cdot 2$ & -0.19 & $-0.76,0.38$ \\
\hline
\end{tabular}

${ }^{*}$ For details of diet and procedures, see Table 1 and p. 344

†There was a significant period effect for this marker, and corrected statistical analysis was performed according to Pocock (1998).

$\ddagger$ There was significant period-effect interaction for this marker, so statistical analysis was performed between groups in period $\mathrm{I}$.

$\S$ There was a significant effect of green tea extract intervention $(P<0.05)$. 
Table 6. Overall changes in biomarkers of oxidative status and in blood lipids from start to end of periods with controlled diets* (Mean values with their standard deviations)

\begin{tabular}{|c|c|c|c|c|c|c|c|c|c|c|}
\hline \multirow[b]{3}{*}{ Biomarker } & \multicolumn{4}{|c|}{ Restricted diet period I } & \multicolumn{4}{|c|}{ Restricted diet period I } & \multirow{2}{*}{\multicolumn{2}{|c|}{$\begin{array}{c}\text { Habitual diet } \\
\text { End (week 13) }\end{array}$}} \\
\hline & \multicolumn{2}{|c|}{ Start (week 2) } & \multicolumn{2}{|c|}{ End (week 5) } & \multicolumn{2}{|c|}{ Start (week 7) } & \multicolumn{2}{|c|}{ End (week 10) } & & \\
\hline & Mean & SD & Mean & SD & Mean & SD & Mean & SD & Mean & SD \\
\hline Glutathione peroxidase (U/g Hb) & $40 \cdot 3$ & $9 \cdot 0$ & 38.7 & $13 \cdot 8$ & $40 \cdot 8$ & $14 \cdot 8$ & 41.9 & $9 \cdot 4$ & $35 \cdot 6 \ddagger$ & $12 \cdot 1$ \\
\hline Glutathione reductase $(\mathrm{U} / \mathrm{g} \mathrm{Hb})$ & $7 \cdot 20$ & 1.11 & 7.05 & $1 \cdot 12$ & $7 \cdot 01$ & 1.08 & $7 \cdot 06$ & $1 \cdot 21$ & $7 \cdot 50 \neq \ddagger$ & 0.83 \\
\hline Superoxide dismutase $(\mathrm{U} / \mathrm{g} \mathrm{Hb})$ & 1035 & 177 & 1011 & 158 & 1019 & 154 & 1034 & 128 & $1098 \ddagger$ & 105 \\
\hline Catalase (U/g Hb) & $11 \cdot 8$ & 1.8 & $11 \cdot 7$ & $2 \cdot 3$ & $12 \cdot 1$ & $2 \cdot 6$ & 11.4 & 1.4 & 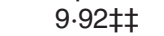 & $1 \cdot 16$ \\
\hline AASpl (nmol/mg protein) & 21.6 & 3.4 & $20 \cdot 0$ & $4 \cdot 2$ & $18 \cdot 6$ & 4.4 & $18 \cdot 3$ & 3.0 & 29.0††† & $8 \cdot 3$ \\
\hline AAShb (nmol/mg protein) & 37.4 & $5 \cdot 1$ & $35 \cdot 9$ & 4.9 & $36 \cdot 1$ & $5 \cdot 3$ & $36 \cdot 6$ & 4.5 & $38 \cdot 9$ & 4.9 \\
\hline GGShb (nmol/mg protein) & $23 \cdot 3$ & $3 \cdot 7$ & $22 \cdot 0$ & 3.6 & $20 \cdot 8$ & $3 \cdot 3$ & 21.5 & $4 \cdot 0$ & $23.4 \ddagger$ & $3 \cdot 2$ \\
\hline Plasma lagtime for lipid marker (min) & 373 & 46 & $457 \uparrow † \uparrow$ & 56 & 430 & 59 & 468††† & 65 & $203 \ddagger \ddagger \ddagger$ & 31 \\
\hline Plasma antioxidant capacity $\left(\mathrm{I}_{\text {ref }}\right)$ & \multicolumn{2}{|c|}{ ND } & 1.35 & 0.21 & \multicolumn{2}{|c|}{ ND } & $1.57 \S$ & 0.22 & \multicolumn{2}{|c|}{ ND } \\
\hline 8-Oxo-dG (pmol/24h per kg body wt) & 337 & 131 & 277††† & 86 & 262 & 90 & 235 & 69 & \multicolumn{2}{|c|}{ ND } \\
\hline Plasma cholesterol $(\mathrm{mmol} / \mathrm{l})$ & 4.13 & 0.98 & 4.24 & 1.04 & 4.39 & 1.08 & 4.22 & 1.20 & $4 \cdot 15$ & 1.03 \\
\hline Plasma triacylglycerol (mmol/l) & $1 \cdot 14$ & $0 \cdot 24$ & 1.03 & 0.25 & 1.31 & 1.41 & $1.03+†$ & $0 \cdot 19$ & $1 \cdot 30 \neq \ddagger \ddagger$ & 0.40 \\
\hline Retinol $(\mu \mathrm{mol} / \mathrm{l})$ & 1.88 & 0.36 & 1.75 & 0.26 & 2.06 & 0.29 & $1.73 † \dagger \dagger$ & 0.30 & $2 \cdot 01 \ddagger \ddagger \ddagger$ & 0.32 \\
\hline Vitamin $C(\mu \mathrm{mol} / \mathrm{l})$ & 43.5 & $18 \cdot 4$ & 16.7††† & $5 \cdot 2$ & $14 \cdot 1$ & $6 \cdot 5$ & $10 \cdot 0$ & 3.46 & 78.4‡†† & $25 \cdot 6$ \\
\hline$\beta$-Carotene $(\mu \mathrm{mol} / \mathrm{l})$ & $0 \cdot 18$ & $0 \cdot 10$ & $1.75 \dagger \dagger \dagger$ & 0.56 & 0.55 & 0.26 & 1.76††† & 0.61 & 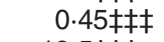 & 0.17 \\
\hline$\alpha$-Tocopherol $(\mu \mathrm{mol} / \mathrm{l})$ & 18.5 & $4 \cdot 1$ & $17 \cdot 7$ & 4.1 & $19 \cdot 6$ & 4.5 & $17 \cdot 4 \dagger \dagger \dagger$ & $4 \cdot 3$ & $19 \cdot 5 \ddagger \ddagger \ddagger$ & $5 \cdot 2$ \\
\hline
\end{tabular}

$\mathrm{Hb}$, haemoglobin; AASpL, plasma 2-amino-adipic semialdehyde; AAShb, 2-amino-adipic semialdehyde in erythrocyte lysates; GGShb, $\gamma$-glutamyl semialdehyde in erythrocyte lysates; Iref, antioxidative capacity relative to reference including Trolox in postprandial plasma samples; 8-oxo-dG, 8-oxo-deoxyguanosine; ND, not determined.

* For details of diet and procedures, see Table 1 and p. 344.

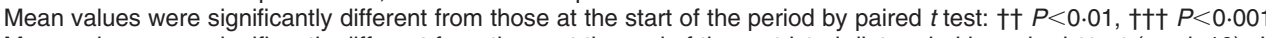

10): $P<0.05$, 拉 $P<0.01$, 扗 $P<0.001$.

Mean value was significantly different from that obtained in week 5: \& $P<0.05$. 

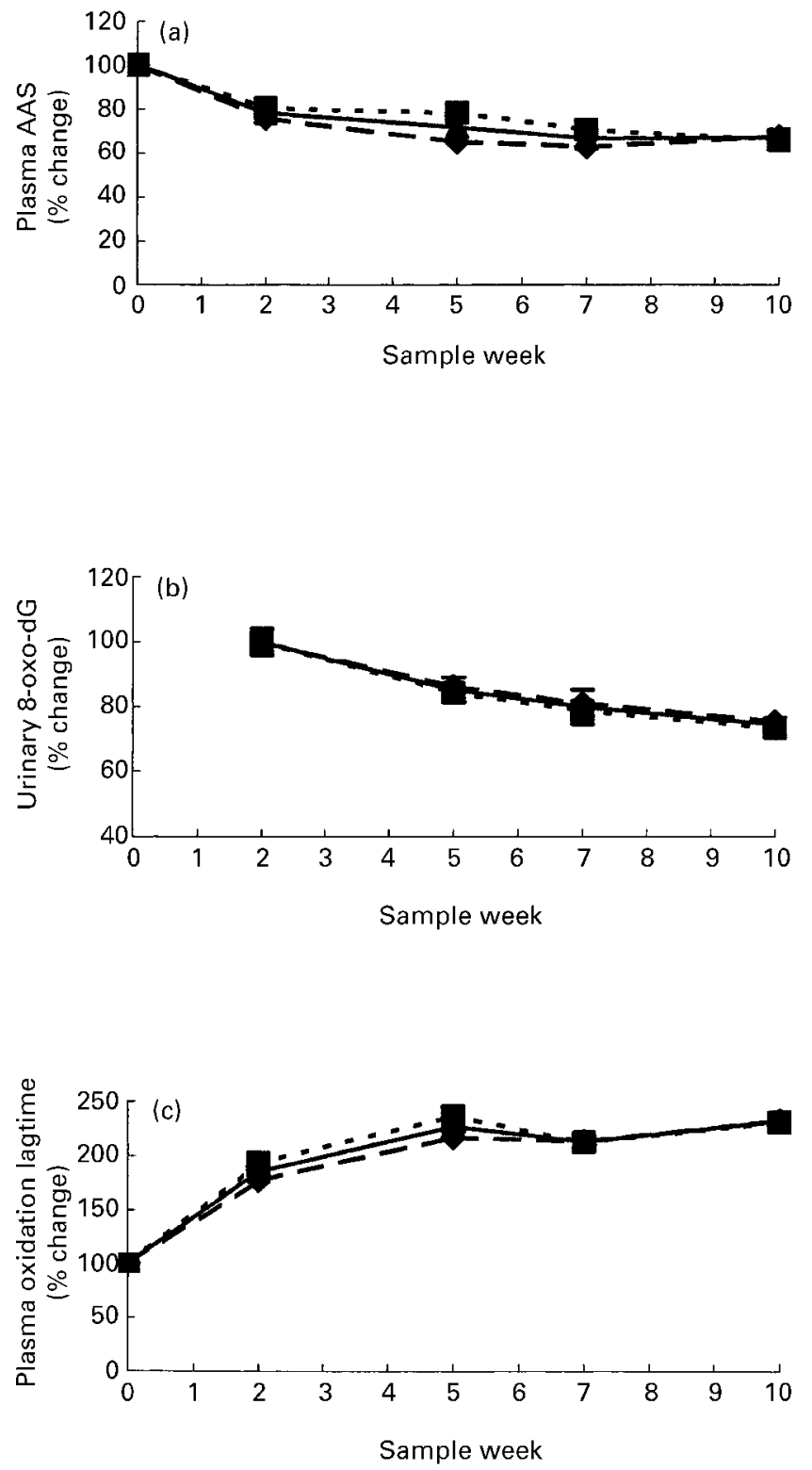

Fig. 2. Biomarkers of oxidative stress (mean values and standard deviations): (a) plasma protein oxidation (2-amino-adipic semialdehyde; AAS); (b) urinary excretion of 8-oxo-deoxyguanosine (8-oxo-dG); (c) plasma total lipoprotein lagtime in sixteen subjects throughout the study period with restricted diets expressed as percentage of the value obtained 3 weeks after its completion (reflecting habitual diet, depicted as day 0). Values for smokers (----), non-smokers (---) and both (- $-\mathbf{\Delta -}$ ) are shown.

intervention periods, and also exhibited a significant overall decrease of 29 (95\% CI 14, 44) \% over time during the 8 weeks on restricted diet (Fig. 2(b)). At baseline (week 2) there were no significant differences between smokers and non-smokers for any of the biomarkers of oxidative stress although the urinary excretion of 8-oxo-dG was $17(95 \%$ CI $-4,48) \%$ higher in smokers than in non-smokers. There were no significant differences between smokers and non-smokers with respect to the changes observed over time for the oxidative damage markers (Figs. 2 and 3).

\section{Enzymes in antioxidant defence}

No changes were observed in activities of the antioxidative enzymes superoxide dismutase, glutathione peroxidase, glutathione reductase and catal in erythrocytes after intervention and none of these markers were affected by smoking status at baseline.

All the enzyme activities were fairly stable during the periods with restricted diets, but changed markedly as the volunteers returned to their habitual diets. Superoxide dismutase and glutathione reductase increased when the restricted diet was substituted for the habitual diet as determined by paired comparisons. Glutathione peroxidase and catalase decreased (Table 6).

\section{Total antioxidative capacity in postprandially collected plasma}

There was a significant period effect for plasma antioxidative capacity. The capacity was higher in the second period. Plasma antioxidative capacity increased significantly overall as determined by paired $t$ test and the increase remained after correction for the period effect (Table 4). The effect was most pronounced in group B which had GTE in the second period. The effect was not significant overall in the non-smokers but was significantly increased among the smokers after intervention with tea extract.

\section{Plasma cholesterol and triacylglycerol}

Cholesterol and triacylglycerol in plasma were not affected by tea extract intervention (Table 5). Tea extract did not affect these markers in either smokers or non-smokers.

Plasma cholesterol and triacylglycerol did not differ between the groups A and B or between smokers and non-smokers at baseline (week 2). Triacylglycerols in plasma decreased significantly in the last intervention period, and also increased when the volunteers returned to their habitual diets.

\section{Vitamin $C$ in diet and plasma}

The calculated content of vitamin $\mathrm{C}$ in the diet is listed in Table 2. Plasma ascorbate was significantly lower in smokers than in non-smokers on their habitual diets. The actual ascorbic acid content of the intervention diet was below the detection limit, i.e. $<1 \mathrm{mg} / 100 \mathrm{~g}$ diet, but the dehydroascorbic acid content was $12.6 \mathrm{mg} / 10 \mathrm{MJ}$ per $\mathrm{d}$. There was no effect of the GTE intervention on plasma ascorbate, neither on total plasma vitamin $\mathrm{C}$ (Table 5), nor when smokers and non-smokers were analysed separately.

Compared with the reference blood sample reflecting habitual diet (week 13), the plasma vitamin C concentration decreased steeply within the first 2 weeks of the study by $36 \%$ resulting in a total decrease by $85 \%$ at the end of the 10th week (Table 6), similar for smokers and non-smokers (Fig. 3(a)). 

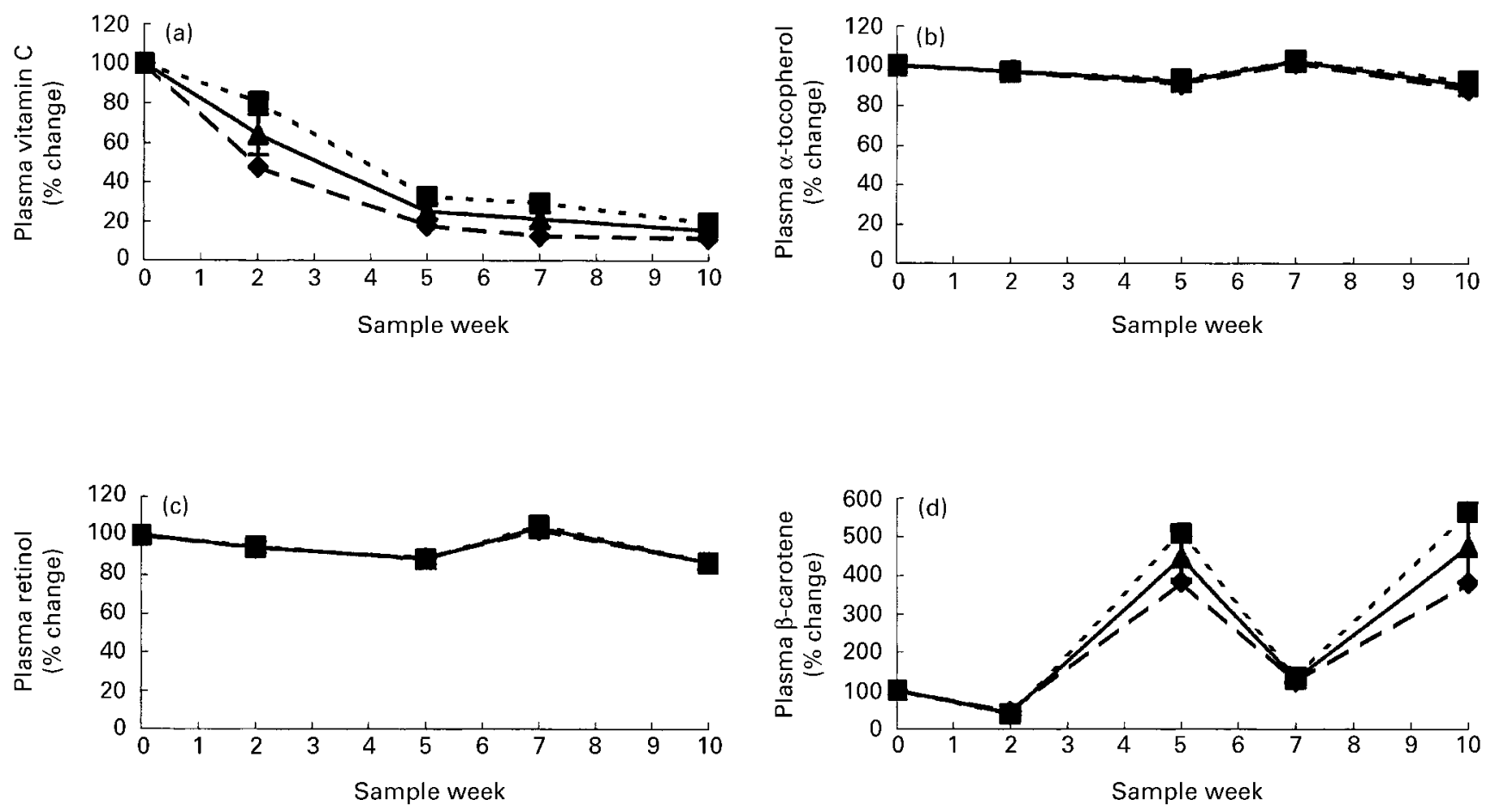

Fig. 3. Plasma concentrations of antioxidant vitamins (mean values and standard deviations): (a) vitaminC; (b) $\alpha$-tocopherol; (c) retinol; (d) $\beta$-carotene in sixteen subjects throughout the study period with restricted diets expressed as percentage of the value obtained 3 weeks after its completion (reflecting habitual diet, depicted as day 0$)$. Values for smokers (----), non-smokers (-- --$)$ and both (- - ) are shown.

\section{Plasma $\alpha$-tocopherol, retinol and $\beta$-carotene}

Plasma $\alpha$-tocopherol and retinol were not affected by intervention with tea extract in either smokers or non-smokers (Table 5).

There was a small decrease by $16 \%$ and $11 \%$, respectively, from start to end of the second intervention period in plasma retinol and $\alpha$-tocopherol (Table 6). Similar decreases were observed in smokers and non-smokers between habitual and intervention diet (Fig. 3).

The basal intervention diet had a relatively high content of $\beta$-carotene, $11.2 \mathrm{mg} / 10 \mathrm{MJ}$ per $\mathrm{d}$, which meant that mean daily intake was $16.2 \mathrm{mg} / \mathrm{d}$, similar in group A and B (range $13.4-20.2 \mathrm{mg} / \mathrm{d}$ ) and that plasma $\beta$-carotene increased significantly during both intervention periods. There was a significant decrease in $\beta$-carotene after the last intervention when compared with the level after 3 weeks with habitual diet. The $\beta$-carotene plasma levels did not reach baseline levels within the wash-out period giving rise to carry-over from the first to the second intervention period (Fig. 3). When tested at the end of the first intervention period tea extract had an increasing effect upon the plasma $\beta$ carotene level (Table 5). Group A had a uniformly larger increase in $\beta$-carotene than group B in both periods, indicating that this was not due to the tea extract. The response was not influenced by smoking status.

\section{Catechins in urine}

The analysis for catechins was very sensitive with a detection limit of $0.5 \mathrm{ng} / \mathrm{ml}$ urine and linearity in the range of
$0 \cdot 5-50 \mathrm{ng} / \mathrm{ml}\left(r^{2}\right.$ 0.998). The standards were stable in the HPLC vials for up to 1 week at room temperature, and at $-20^{\circ} \mathrm{C}$ for 3 months.

In the first follow-up study we observed that $80 \%$ of the excreted EC and EGC were detected in urine within $4 \mathrm{~h}$, whereas $20 \%$ were excreted between 4 and $24 \mathrm{~h}$. At $48 \mathrm{~h}$ no catechins were detectable (see Fig. 4). This points to an excretion half-life of about $1.6 \mathrm{~h}$ for both substances. There was good concordance between double determinations for each individual (CV was $6.1 \%$ for $\mathrm{EC}$ and $5.3 \%$ for EGC), but relatively large inter-individual variations in total excretion (CV was $27 \%$ for EC and $19 \%$ for EGC). A mean of $3.2 \%$ of EC and $1.3 \%$ of EGC was excreted in the first follow-up study.

In the second follow-up study, EC and EGC were observed in 24-h urine samples from each of the three volunteers on the days where GTE was ingested, whereas only a trace was found in urine from day 2 where the volunteers had abstained from catechin-containing foods for $24 \mathrm{~h}$, (see Table 7). After correcting for the recovery of catechin in each sample, $3.7 \%$ of the EC and $2.8 \%$ of the EGC from the ingested GTE were found in the urine. EC and EGC were excreted in urine after ingestion of the same GTE-containing meat patties which were used in the main study, indicating that EC and EGC are absorbable from enriched meat patties.

\section{Discussion}

It is still controversial whether green tea can protect against cancer and heart disease (Goldbohm et al. 1996; Katan, 

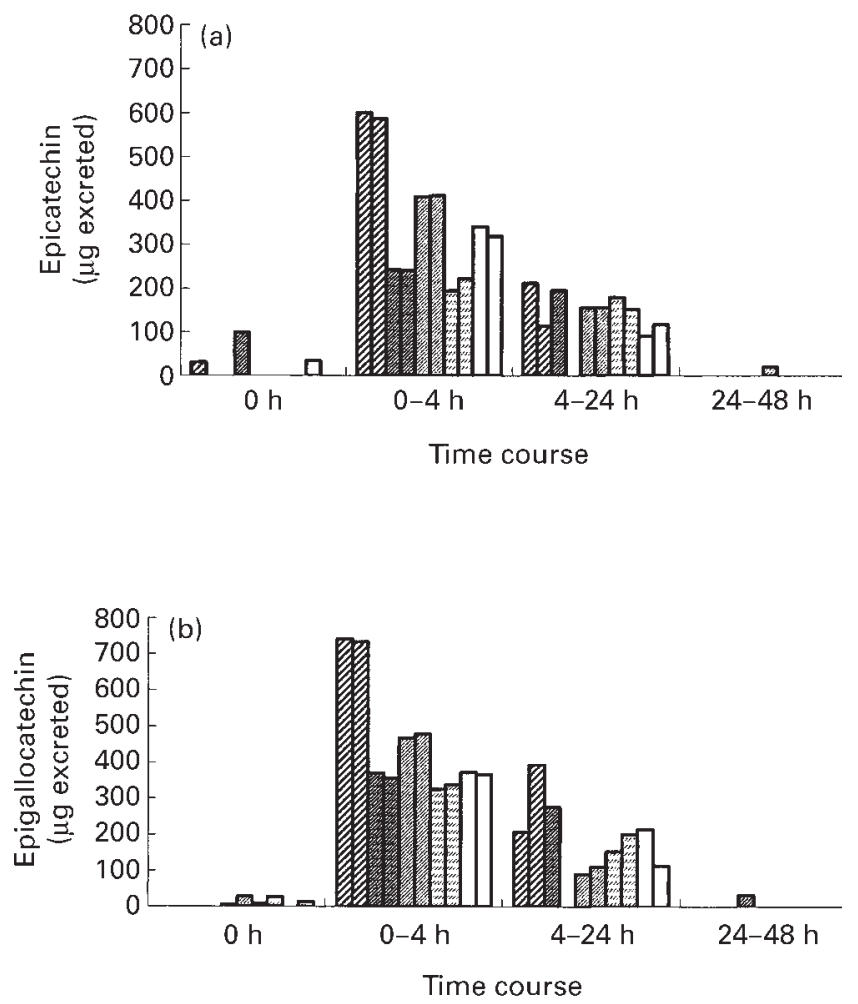

Fig. 4. Urinary excretion of (a) epicatechin and (b) epigallocatechin in five volunteers $(\square, \mathbb{Z}, \mathbb{2}, \square)$ at various intervals up to $48 \mathrm{~h}$ after ingestion of $2 \mathrm{~g}$ green tea extract containing $16.3 \mathrm{mg}$ epicatechin and $51.4 \mathrm{mg}$ epigallocatechin. Each sample was analysed in duplicate and the total amounts excreted in each interval are shown as bars.

1997; Kohlmeier et al. 1997), but the high content of antioxidants in green tea, catechins in particular, has been suggested to cause such effects through a protective mechanism against radical-mediated damage (Imai \& Nakachi, 1995; Benzie et al. 1999; Klaunig et al. 1999). Although green or black tea, tea extracts or isolated catechins have shown potent protective effects against oxidative stress in various model systems in vitro and in animal experiments (Loft \& Poulsen, 1999), recent studies with human subjects have recorded limited effects in accordance with our present results. Van het Hof et al. (1997) did not observe any effects on resistance to LDL oxidation, plasma lipid oxidation or antioxidative enzyme activities in volunteers

Table 7. Excretion of epigallocatechin (EGC) and epicatechin (EC) after intake of green tea extract in three different regimens*

\begin{tabular}{|c|c|c|c|c|}
\hline \multirow[b]{2}{*}{ Diet } & \multicolumn{2}{|c|}{ EGC† } & \multicolumn{2}{|c|}{ EC† } \\
\hline & Mean & SD & Mean & SD \\
\hline Enriched meat patties $\ddagger$ & 2.02 & 1.00 & $2 \cdot 73$ & 1.26 \\
\hline Meat patties with added extract§ & $2 \cdot 12$ & 0.06 & $2 \cdot 62$ & 1.75 \\
\hline Extract only & 2.68 & 0.83 & $3 \cdot 20$ & 0.57 \\
\hline
\end{tabular}

${ }^{*}$ For details of procedures, see p. 344.

$\dagger$ Expressed as percentage of ingested amount.

$\ddagger$ Enriched during production and stored for 12 months at $-25^{\circ} \mathrm{C}$

$\S$ Green tea extract added right before ingestion. after intake of tea for 2 weeks. Similarly, black tea polyphenols increased the resistance of human plasma to lipid peroxidation in vitro but not ex vivo after ingestion of black tea (Cherubini et al. 1999).

The present study included a group of smokers with a potentially higher oxidative stress. In a cross-sectional study Imai \& Nakachi (1995) observed a decrease in lipid peroxides in fasting blood samples from heavy smokers who took ten cups of green tea/d or more, but Princen et al. (1998) did not observe any effect on LDL-oxidation, cholesterol levels, or plasma triacylglycerols in a randomised controlled study on smokers receving six cups of black or green tea a day for 4 weeks. In the present study we did not observe differences between smokers and non-smokers in fasting blood samples using any of the selected markers of oxidative status or lipid status either before or after intervention with catechin-rich tea extract after what corresponds to a more ordinary intake of about 1-2 cups of tea/d which is within the estimated median intake of 20-50 mg daily of catechins in Denmark (Dragsted et al. 1997). As expected, the smokers in the present study had lower ascorbate levels in plasma samples representing habitual diet. In the postprandial samples we observed a significant effect of GTE intervention on plasma antioxidant capacity in smokers only, when smokers and non-smokers were analysed separately, indicating that GTE has a more prominent effect in oxidatively stressed individuals. Thus, our observations in smokers is in fair agreement with the results of others although the dose of catechins in the present study may not have been sufficiently large for an effect on lipid oxidation.

The unexpectedly high bioavailability of $\beta$-carotene caused significant period-effect interactions and when analysed at the end of the first intervention period, tea extract seemed to increase plasma $\beta$-carotene. A sparing effect of GTE catechins on plasma $\beta$-carotene can therefore not be excluded to be present also in vivo. However, there is a large inter-individual variation in response to $\beta$-carotene, and extreme subjects are sometimes characterised as 'non-responders' and 'high-responders', respectively (Bowen et al. 1993; Parker, 1996). In the present study the larger response in group A, observed in both intervention periods, seemed to be due to a larger number of 'high-responders' in this group and we therefore conclude that GTE probably had no true sparing effect on $\beta$-carotene in the present study. This is in line with the observation that plasma $\beta$-carotene did not have a timecourse similar to any markers of free-radical mediated damage in the present study.

Results of our follow-up studies indicate that as much as $2.7 \%$ of the dose of EC and $2.0 \%$ of EGC may have been absorbed from the meat patties fortified with catechins, but that excretion is very fast with urinary excretion half-lives of less than $2 \mathrm{~h}$. The protein-rich matrix did not seem to greatly influence catechin uptake in accordance with results concerning other polyphenols (Hollman et al. 1997). Nakagawa et al. (1997) have shown that up to $2 \%$ epigallocatechin gallate and $1.3 \% \mathrm{EGC}$ are incorporated into plasma 90 min after ingestion of GTE in capsules in fair agreement with our results. Our results on antioxidant vitamins in plasma also confirm the results of others, who did not 
see any changes in tocopherols, $\beta$-carotene, ascorbic acid or uric acid after consumption of teas or tea extracts at 5-20 times higher doses than ours but with less control over dietary intakes (Nakagawa et al. 1997; van het Hof et al. 1997).

We observed that the antioxidant capacity increased, as measured $2 \mathrm{~h}$ after a tea extract-containing meal. This effect on the antioxidative capacity in plasma confirms the results of several others (van het Hof et al. 1997; Pietta et al. 1998; Benzie et al. 1999; Sung et al. 2000) who also observed an increased total antioxidant activity in plasma shortly after consumption of a single or multiple doses of green or black tea. The presence of only a shortterm effect may readily be explained by the short half-life of catechins from GTE as seen in Fig. 4.

The lack of long-term effects from the GTE intervention allows for a post-hoc analysis of the longitudinal effects of a flavonoid-free diet on the biomarkers of oxidative damage and defence in the present study. We have previously observed a significant increase in plasma AAS after high intakes of juices rich in ascorbate and plant phenols (Young et al. 1999) and Castenmiller et al. (1999) observed a significant correlation between plasma ascorbate and plasma AAS among sixty-four volunteers in a spinach intervention study (Castenmiller et al. 1999). We have also observed a decrease in plasma ascorbate and in plasma protein oxidation in a recent study over a period of 2 weeks with a fruit- and vegetable-free diet similar to the one used in the present study (Young et al. 2000). It is possible that dietary changes induced a change in protein turnover or degradation. However, a similar decrease in protein oxidation, in 8 -oxo-dG excretion and in the increased resistance of plasma lipoproteins to oxidation in the present study points to a more general relief of oxidative stress after depletion of flavonoid- and ascorbaterich fruits and vegetables from the diet, contrary to common beliefs.

The decrease in the urinary excretion of 8-oxo-dG might also have resulted from a decrease in the efficiency of DNA-repair. Other studies on DNA damage in relation to fruit and vegetable intakes show an equivocal picture (Velthuis-te Wierik et al. 1995; Hertog et al. 1997; Djuric et al. 1998), whereas no significant effect of vitamin $\mathrm{C}$, vitamin $\mathrm{E}$ or $\beta$-carotene on the excretion of 8 -oxo-dG has been observed in placebo-controlled intervention studies and in meta-analyses (van Poppel et al. 1995; Priemé et al. 1997; Poulsen et al. 1998; Loft \& Poulsen, 2000). Studies on plasma lipid oxidation, plasma oxidation lagtimes and plasma malondialdehyde in relation to diet generally point to an increase in oxidative damage with diets low in fruits, vegetables or vitamin $\mathrm{C}$, in disagreement with our findings (Fuller et al. 1996; Omaye et al. 1996; Anderson et al. 1997; Miller et al. 1998; Maskarinec et al. 1999). Complex pro- and antioxidant effects could together with large differences in study material and protocols possibly explain much of the apparent extensive variation and discrepancies regarding the effects of antioxidants, fruits and vegetables on DNA, lipid and protein oxidation.

In conclusion, GTE incorporated into meat patties in doses realistic for addition to processed foods only leads to a short-term change in plasma antioxidant capacity and has no long-term effects on oxidation parameters within the blood or urine compartments in smokers or in non-smokers. The study can therefore be seen as a 10 weeks controlled study with dietary depletion of all food antioxidants derived from fruits and vegetables, except for carrots and potatoes. During the depletion we observed a decrease in oxidative damage to proteins, DNA, and lipids, concomitantly with a major reduction in plasma ascorbate and minor changes in other vitamins and in antioxidant enzyme activities. We speculate that these seemingly positive effects on oxidative status are partly due to depletion of some pro-oxidant compounds co-existing with vitamin $\mathrm{C}$ in fruits and vegetables and this underlines the general lack of solid knowledge of the mechanisms by which a diet rich in fruits and vegetables cause a decrease in the risk of chronic diseases.

\section{Acknowledgements}

The authors wish to thank Anni Schou, Vibeke Kegel, Joan Frandsen, Hanne Fenger Eriksen, Susanne M. Hansen, Birgitte Alstrup Jørgensen, and Ella Jessen for excellent assistance, and Nestlé R\&D Bjuv (Sweden) for providing the meat products used in this study.

\section{References}

Aeschbach R \& Rossi P (1994) Alkylene glycol extraction of antioxidants from vegetable matter. Nestec Ltd. (US patent US5795609).

Anderson D, Phillips BJ, Yu TW, Edwards AJ, Ayesh R \& Butterworth KR (1997) The effects of vitamin C supplementation on biomarkers of oxygen radical generated damage in human volunteers with low or high cholesterol levels. Environmental and Molecular Mutagenesis 30, 161-174.

Benzie IFF, Szeto YT, Strain JJ \& Tomlinson B (1999) Consumption of green tea causes rapid increase in plasma antioxidant power in humans. Nutrition and Cancer 34, 83-87.

Bowen PE, Garg V, Stacewicz-Sapuntzakis M, Yelton L \& Schreiner RS (1993) Variability of serum carotenoids in response to controlled diets containing six servings of fruits and vegetables per day. Annals of the New York Academy of Sciences 691, 241-243.

Castenmiller JJM, Lauridsen ST, Dragsted LO, van het Hof KH, Linssen JPH \& West CE (1999) Beta-carotene does not change markers of enzymatic and non-enzymatic antioxidant activity in human blood. Journal of Nutrition 129, 2162-2169.

Cherubini A, Beal MF \& Frei B (1999) Black tea increases the resistance of human plasma to lipid peroxidation in vitro, but not ex vivo. Free Radical Biology and Medicine 27, 381-387.

Daneshvar B, Frandsen H, Autrup H \& Dragsted LO (1997) Gamma-glutamyl semialdehyde and 2-amino-adipic semialdehyde: biomarkers of oxidative damage to proteins. Biomarkers 2, 117-123.

Das NP (1971) Studies of flavonoid metabolism. Absorption and metabolism of (+)-catechin in man. Biochemical Pharmacology 20, 3435-3445.

Djuric Z, Depper JB, Uhley V, Smith D, Lababidi S, Martino S \& Heilbrun LK (1998) Oxidative DNA damage levels in blood from women at high risk for breast cancer are associated with dietary intakes of meats, vegetables, and fruits. Journal of the American Dietetics Association 98, 524-528.

Dragsted LO, Strube M \& Leth T (1997) Dietary levels of plant 
phenols and other non-nutritive components: could they prevent cancer? European Journal of Cancer Prevention 6, $522-528$.

Fuller CJ, Grundy SM, Norkus EP \& Jialal I (1996) Effect of ascorbate supplementation on low density lipoprotein oxidation in smokers. Atherosclerosis 119, 139-150.

Gardner PT, McPhail DB \& Duthie GC (1998) Electron spin resonance spectroscopic assessment of the antioxidant potential of teas in aqueous and organic media. Journal of the Science of Food and Agriculture 76, 257-262.

Goldbohm RA, Hertog MGL, Brants HAM, van Poppel G \& van den Brandt PA (1996) Consumption of black tea and cancer risk: A prospective cohort study. Journal of the National Cancer Institute 88, 93-100.

Hart DJ \& Scott KJ (1995) Development and evaluation of an HPLC method for the analysis of carotenoids in foods, and the measurement of the carotenoid content of vegetables and fruits commonly consumed in the UK. Food Chemistry 54, $101-111$.

Hertog MGL, de Vries A, Ocké MC, Schouten A, Bueno-de-Mesquita HB \& Verhagen H (1997) Oxidative DNA damage in humans: comparison between high and low habitual fruit and vegetable consumption. Biomarkers 2, 259-262.

Hertog MGL, Feskens EJM, Hollman PCH, Katan MB \& Kromhout D (1993a) Dietary antioxidant flavonoids and risk of cornary heart disease: the Zutphen elderly study. Lancet $\mathbf{3 4 2}$, 1007-1011.

Hertog MGL, Feskens EJM, Hollman PCH, Katan MB \& Kromhout D (1994) Dietary flavonoids and cancer risk in the Zutphen elderly study. Nutrition and Cancer 22, 175-184.

Hertog MGL, Hollman PCH, Katan MB \& Kromhout D (1993b) Estimation of daily intake of potentially anticarcinogenic flavonoids and their determinats in adults in The Netherlands. Nutrition and Cancer 20, 21-29.

Hertog MGL, Kromhout D, Aravanis C, Blackburn H, Buzina R, Fidanza F, Giampaoli S, Jansen A, Menotti A, Nedeljkovic S, Pekkarinen M, Simic BS, Toshima H, Feskens EJM, Hollman $\mathrm{PCH} \&$ Katan MB (1995) Flavonoid intake and long-term risk of coronary heart disease and cancer in The Seven Countries Study. Archives of Internal Medicine 155, 381-386.

Hofer G, Lichtenberg D \& Hermetter A (1995) A new fluorescence method for the continuous determination of surface lipid oxidation in lipoproteins and plasma. Free Radical Research 23, 317-327.

Hollman PC, Tijburg LB \& Yang CS (1997) Bioavailability of flavonoids from tea. Critical Reviews of Food Science and Nutrition 37, 719-738.

Imai K \& Nakachi K (1995) Cross sectional study of effects of drinking green tea on cardiovascular and liver diseases. British Medical Journal 310, 693-696.

Ishikawa T, Suzukawa M, Ito T, Yoshida H, Ayaori M, Nishiwaki M, Yonemura A, Hara Y \& Nakamura H (1997) Effect of tea flavonoid supplementation on the susceptibility of low-density lipoprotein to oxidative modification. American Journal of Clinical Nutrition 66, 261-266.

Jørgensen K \& Skibsted L (1993) Carotenoid scavenging of radicals. Effects of carotenoid structure and oxygen partial pressure on antioxidative activity. Zeitschrift für Lebensmittel Untersuchung und Forschung 196, 423-429.

Kall M \& Andersen C (1999) Improved method for simultaneous determination of ascorbic acid and dehydroascorbic acid, isoascorbic acid and dehydroisoascorbic acid in food and biological samples. Journal of Chromatography B: Biomedical Sciences and Applications 730, 101-111.

Katan MB (1997) Flavonoids and heart disease. American Journal of Clinical Nutrition 65, 1542-1543.

Klaunig JE, Xu Y, Han C, Kamendulis LM, Chen J, Heiser C,
Gordon MS \& Mohler ER III (1999) The effect of tea consumption on oxidative stress in smokers and nonsmokers. Proceedings of the Society Experimental Biology and Medicine 220, 249-254.

Kohlmeier L, Weterings KG, Steck S \& Kok FJ (1997) Tea and cancer prevention: an evaluation of the epidemiologic literature. Nutrition and Cancer 27, 1-13.

Lin J-K, Lin C-L, Liang Y-C, Lin-Shiau S-Y \& Juan I-M (1998) Survey of catechins, gallic acid, and methylxanthines in green, oolong, pu-erh, and black teas. Journal of Agricultural Food Chemistry 46, 3635-3642.

Loft S \& Poulsen HE (1999) Markers of oxidative damage to DNA: antioxidants and molecular damage. Methods in Enzymology 300, 166-184.

Loft S \& Poulsen HE (2000) Antioxidant intervention studies related to DNA damage, DNA repair and gene expression. Free Radical Research 33, S67-S83.

Lotito SB \& Fraga CG (1998) (+)-Catechin prevents human plasma oxidation. Free Radical Biology and Medicine 24, 435-441.

Maskarinec G, Chan CL, Meng L, Franke AA \& Cooney RV (1999) Exploring the feasibility and effects of a high-fruit and -vegetable diet in healthy women. Cancer Epidemiology Biomarkers and Prevention 8, 919-924.

Miller ER III, Appel LJ \& Risby TH (1998) Effect of dietary patterns on measures of lipid peroxidation: results from a randomized clinical trial. Circulation 98, 2390-2395.

Møller A (1989) Food Composition tables. Copenhagen: National Food Agency.

Nakagawa K \& Miyazawa T (1997) Absorption and distribution of tea catechin, (-)- epigallocatechin-3-gallate, in the rat. Journal of Nutritional Science and Vitaminology 43, 679-684.

Nakagawa K, Okuda S \& Miyazawa T (1997) Dose-dependent incorporation of tea catechins, (-)- epigallocatechin-3-gallate and (-)-epigallocatechin, into human plasma. Bioscience Biotechnology Biochemistry 61, 1981-1985.

Nielsen SE \& Dragsted LO (1998a) Column-switching high-performance liquid chromatographic assay for the determination of quercetin in human urine with ultraviolet absorbance detection. Journal of Chromatography 707B, 81-89.

Nielsen SE \& Dragsted LO (1998b) Column-switching high-performance liquid chromatographic assay for determination of apigenin and acacetin in human urine with ultraviolet absorbance detection. Journal of Chromatography 713B, 379-386.

Nielsen SE, Young JF, Daneshvar B, Lauridsen ST, Knuthsen P, Sandström B \& Dragsted LO (1999) Effect of parsley (Petroselinum crispum) intake on urinary apigenin excretion, blood antioxidant enzymes and biomarkers for oxidative stress in human subjects [see comments]. British Journal of Nutrition 81, 447-455.

Nissen LR, Mansson L, Bertelsen G, Huynh-Ba T \& Skibsted LH (2000) Protection of dehydrated chicken meat by natural antioxidants as evaluated by electron spin resonance spectrometry. Journal of Agricultural and Food Chemistry 48, 5548-5556.

Omaye ST, Burri BJ, Swendseid ME, Henning SM, Briggs LA, Bowen HT \& Ota RB (1996) Blood antioxidants changes in young women following beta-carotene depletion and repletion. Journal of the American College of Nutrition 15, 469-474.

Parker RS (1996) Absorption, metabolism, and transport of carotenoids. FASEB Journal 10, 542-551.

Pietta P, Simonetti P, Gardana C, Brusamolino A, Morazzoni P \& Bombardelli E (1998) Relationship between rate and extent of catechin absorption and plasma antioxidant status. Biochemistry and Molecular Biology International 46, 895-903.

Pocock SJ (1998) Clinical Trials. A Practical Approach. Chichester, UK: Wiley \& Sons.

Poulsen HE, Prieme H \& Loft S (1998) Role of oxidative DNA 
damage in cancer initiation and promotion. European Journal of Cancer Prevention 7, 9-16.

Priemé H, Loft S, Nyyssönen K, Salonen JT \& Poulsen HE (1997) No effect of supplementation with vitamin E, ascorbic acid, or coenzyme Q10 on oxidative DNA damage estimated by 8-oxo-7,8-dihydro-2'-deoxyguanosine excretion in smokers. American Journal of Clinical Nutrition 65, 503-507.

Princen HM, van Duyvenvoorde W, Buytenhek R, Blonk C, Tijburg LB, Langius JA, Meinders AE \& Pijl H (1998) No effect of consumption of green and black tea on plasma lipid and antioxidant levels and on LDL oxidation in smokers. Arteriosclerosis Thrombosis and Vascular Biology 18, 833-841.

Serafini M, Ghiselli A \& Ferro LA (1996) In vivo antioxidant effect of green and black tea in man. European Journal of Clinical Nutrition 50, 28-32.

Sung H, Nah J, Chun S, Park H, Yang SE \& Min WK (2000) In vivo antioxidant effect of green tea (In Process Citation). European Journal of Clinical Nutrition 54, 527-529.

Thurnham DI, Smith E \& Flora PS (1988) Concurrent liquidchromatographic assay of retinol, alpha-tocopherol, beta-carotene, alpha-carotene, lycopene, and beta-cryptoxanthin in plasma, with tocopherol acetate as internal standard. Clinical Chemistry 34, 377-381.

van het Hof KH, de Boer HSM, Wiseman SA, Lien N, Weststrate JA \& Tijburg LBM (1997) Consumption of green or black tea does not increase resistance of low-density lipoprotein to oxidation in humans. American Journal of Clinical Nutrition 66, 1125-1132.

van Poppel G, Poulsen H, Loft S \& Verhagen H (1995) No influence of beta-carotene on oxidative DNA damage in male smokers. Journal of the National Cancer Institute 87, 310-311.

Velthuis-te Wierik EJ, van Leeuwen RE, Hendriks HF, Verhagen H, Loft S, Poulsen HE \& van den BH (1995) Short-term moderate energy restriction does not affect indicators of oxidative stress and genotoxicity in humans. Journal of Nutrition 125, 2631-2639.

Yen G \& Chen H (1995) Antioxidant activity of various tea extracts in relation to their antimutagenicity. Journal of Agricultural and Food Chemistry 43, 27-32.

Young JF, Dragsted LO, Daneshvar B, Lauridsen ST, Hansen M \& Sandström B (2000) The effect of grape skin extract on oxidative status. British Journal of Nutrition 84, 505-513.

Young JF, Nielsen SE, Haraldsdóttir J, Daneshvar B, Lauridsen ST, Knuthsen P, Crozier A, Sandström B \& Dragsted LO (1999) Effect of fruit juice intake on urinary quercetin excretion and biomarkers of antioxidative status. American Journal of Clinical Nutrition 69, 87-94.

Zhang A, Chan PT, Luk YS, Ho WKK \& Chen ZY (1997) Inhibitory effect of jasmine green tea epicatechin isomers on LDLoxidation. Nutritional Biochemistry 8, 334-340. 